\title{
Observer-Based Tuning of Two-Inertia Servo-Drive Systems With Integrated SAW Torque Transducers
}

\author{
Timothy M. O'Sullivan, Christopher M. Bingham, Member, IEEE, and Nigel Schofield
}

\begin{abstract}
This paper proposes controller design and tuning methodologies that facilitate the rejection of periodic load-side disturbances applied to a torsional mechanical system while simultaneously compensating for the observer's inherent phase delay. This facilitates the use of lower-bandwidth practically realizable disturbance observers. The merits of implementing full- and reduced-order observers are investigated, with the latter being implemented with a new low-cost servo-machine-integrated highbandwidth torque-sensing device based on surface acoustic wave (SAW) technology. Specifically, the authors' previous work based on proportional-integral-derivative (PID) and resonance ratio control (RRC) controllers (IEEE Trans. Ind. Electron., vol. 53, no. 4, pp. 1226-1237, Aug. 2006) is augmented with observer disturbance feedback. It is shown that higher-bandwidth disturbance observers are required to maximize disturbance attenuation over the low-frequency band (as well as the desired rejection frequency), thereby attenuating a wide range of possible frequencies. In such cases, therefore, it is shown that the RRC controller is the preferred solution since it can employ significantly higher observer bandwidth, when compared to PID counterparts, by virtue of reduced noise sensitivity. Furthermore, it is demonstrated that the prototype servo-machine-integrated $20-\mathrm{N} \cdot \mathrm{m}$ SAW torque transducer is not unduly affected by machine-generated electromagnetic noise and exhibits similar dynamic behavior as a conventional instrument inline torque transducer.
\end{abstract}

Index Terms-Filter noise, motion control, motor drives, observers, resonance, state feedback, surface acoustic wave (SAW) devices, velocity control.

\section{NOMENCLATURE}

$J_{m} \quad$ Motor inertia (in kilogram square meters).

$J_{d} \quad$ Load inertia (in kilogram square meters).

$K_{m d}$ Interconnecting shaft stiffness (in newton meters per radian).

$R \quad$ Inertia ratio $J_{d} / J_{m}$.

$\tilde{J}_{m} \quad$ "Virtual" motor inertia (in kilogram square meters).

$\tilde{R} \quad$ "Virtual" inertia ratio.

$t_{e} \quad$ Controller output electromagnetic torque demand (assumed to be equivalent to actual electromagnetic torque; in newton meters).

$t_{d} \quad$ Load-side torque (in newton meters).

Manuscript received December 21, 2005; revised October 2, 2006. Abstract published on the Internet January 14, 2007. This work was supported in part by the U.K. Engineering and Physical Sciences Research Council (EPSRC) and in part by Sensor Technology Ltd., Banbury, U.K

T. M. O'Sullivan and C. M. Bingham are with the Electrical Machines and Drives Group, Department of Electronic and Electrical Engineering, University of Sheffield, Sheffield S10 2TN, U.K. (e-mail: c.bingham@sheffield.ac.uk).

N. Schofield is with the Department of Electrical Engineering and Electronics, University of Manchester, Manchester M13 9PL, U.K.

Color versions of one or more of the figures in this paper are available online at http://ieeexplore.ieee.org.

Digital Object Identifier 10.1109/TIE.2007.892743

\author{
$t_{m d} \quad$ Torsional shaft torque (in newton meters). \\ $\omega_{n} \quad$ Mechanical resonant frequency (in radians per second). \\ $\omega_{a}$ Mechanical antiresonant frequency (in radians per \\ second). \\ $\omega_{m} \quad$ Motor angular velocity (in radians per second). \\ $\omega_{d} \quad$ Load angular velocity (in radians per second). \\ $\omega_{q} \quad$ Motor or load angular velocity (when motor and load \\ inertias are connected via an infinitely stiff shaft; in \\ radians per second). \\ $\omega_{r} \quad$ Reference angular velocity (in radians per second). \\ $\omega_{x} \quad$ Load-side closed-loop tracking bandwidth (in radians \\ per second). \\ $K_{p} \quad$ Proportional gain. \\ $K_{i} \quad$ Integral gain. \\ $K_{d} \quad$ Derivative gain. \\ $K_{s} \quad$ Proportional shaft torque gain. \\ $K_{a} \quad$ Derivative shaft torque gain. \\ $K_{p d} \quad$ Proportional disturbance torque gain. \\ $K_{d d} \quad$ Derivative disturbance torque gain. \\ $\omega_{r j} \quad$ Rejection frequency (in radians per second). \\ $x_{m} \quad$ Measured state variables. \\ $x_{e} \quad$ State variables that need to be observed. \\ $\hat{x}_{e} \quad$ Observed state variables. \\ $\hat{t}_{d} \quad$ Observed load torque (in newton meters). \\ $G \quad$ Observer gain matrix. \\ $\omega_{\mathrm{ob}}$ Observer $-3 \mathrm{~dB}$ bandwidth (in radians per second).
}

\section{INTRODUCTION}

$\mathbf{L}$ OW-FREQUENCY periodic disturbances to servo control systems are a common feature of industrial automation systems. By way of example, web handling, where the material is unwound from a roll, processed (coating layer, cutting, etc.), and wound back onto another roll, often creates an increasingly elliptical roll profile that loads the servo system in a cyclic manner [2] - the frequency being determined by the rotational speed of the wind, which changes with the amount of material on the roll in order to maintain a constant web tension. To address such difficulties, it is common to increase the aggressiveness of the servo-drive control action to overcome any tendency to deviate from a reference demand. However, constrained control structures commonly employed in commercial servodrive systems, along with limited power capability and stability margins, place upper limits on the achievable regulation and tracking performance. An alternative is to feed a measurement of load disturbance directly into the power converter (servo amplifier) to provide a countering torque, thereby compensating for the disturbance [2]-[7]—commonly referred to as feedforward disturbance decoupling. 
Rejection of periodic load disturbances in this manner constitutes a classical control problem when the torsional mechanical system interconnecting the motor and load can be considered infinitely stiff, and dynamic load perturbations can be measured or estimated to a sufficiently high bandwidth, via a simple rigid-body observer [8]. In the majority of cases, however, mechanical systems often exhibit low-frequency resonant behavior with a fundamental frequency of $<300 \mathrm{~Hz}$ [9], load torque cannot be directly measured, due to either cost or environmental limitations, and recourse to controllers employing higher-order observers (termed disturbance observer) that provide a realtime dynamic estimate of the disturbance is made [2]-[6], [10]-[13]. For the sake of simplifying the theoretical analysis, state observer dynamics are assumed to be of sufficiently high bandwidth that they can be ignored. However, since feedforward compensation is applied directly into the servo amplifier, its effectiveness is heavily dependent on the ability of the disturbance observer to provide a sufficiently high-bandwidth delay-free estimate of load, since phase delays significantly impede the ability of the controller to compensate effectively, and compromise stability [3], [14]. An unfortunate feature of classical observer schemes is that they are inherently derivative in nature (i.e., they amplify high-frequency sensor noise), and those employed for industrial motion-control applications (where a quantized position signal from an encoder is normally employed) are therefore forced to have significant bandwidth constraints, which is usually $<100 \mathrm{~Hz}$ [9] in order to attenuate high-frequency noise, unmodeled resonant modes, and compensate for additional measurement delays [2], [3], [14], [15]. Moreover, in such cases, the dynamics imparted by the use of a relatively low-bandwidth observer unduly influences the system dynamics, which ultimately affects the desired rejection performance [2], [3], [14]. Consequently, more complex Kalman state estimators have been proposed [4], [10], [13], where the unmodeled dynamics and noise are lumped together and modeled as a Gaussian process. Nevertheless, in practical systems, other characteristics that cannot be modeled by a white noise covariance are inevitably present [9], [16], such as resonant peaks and/or speed-dependent mechanical eccentricities, as well as signal contamination from power-converter highfrequency switching harmonics. Furthermore, the use of these is computationally expensive, and therefore, recently, emphasis has returned to the use of classical observer structures and methodologies to provide maximum benefit by appropriate gain design. However, few algorithms that compensate for the limitations imparted by a relatively low-bandwidth observer exist, particularly in high-performance motion-control applications.

Until recently, difficulties in acquiring reliable low-noise low-cost shaft torque transducers that are noninvasive to the mechanical drive system have precluded the use of measured shaft torque feedback for disturbance rejection in all but a minority of specialized closed-loop servo-drive systems. Often, commonly employed torque transducers, viz., strain gauge and optical and inductive devices, are too mechanically compliant when incorporated in a drive system, thereby degrading stability margins and reducing closed-loop bandwidth. Moreover, the additional cost associated with their integration is prohibitive. Surface acoustic wave (SAW) devices are mechanically robust, exhibit

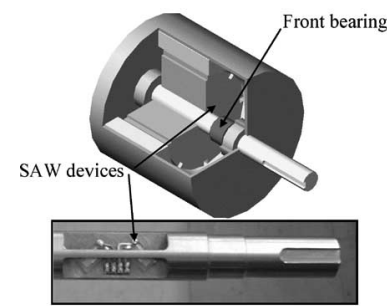

(a)

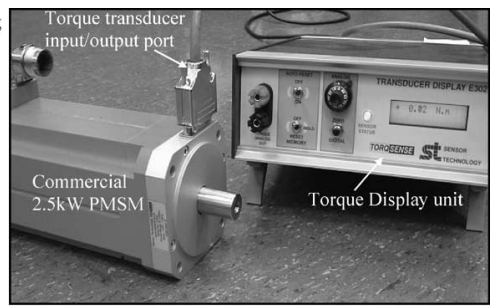

(b)
Fig. 1. PMSM with integrated 20-N $\cdot \mathrm{m}$ SAW torque transducer. (a) Illustration of the servo machine showing the location of SAW devices and RF module. (b) Prototype servo machine.

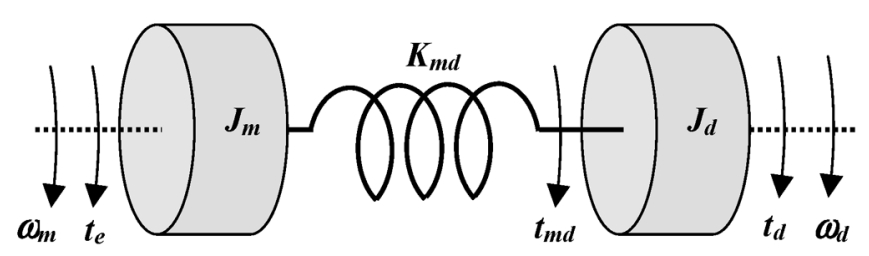

(a)

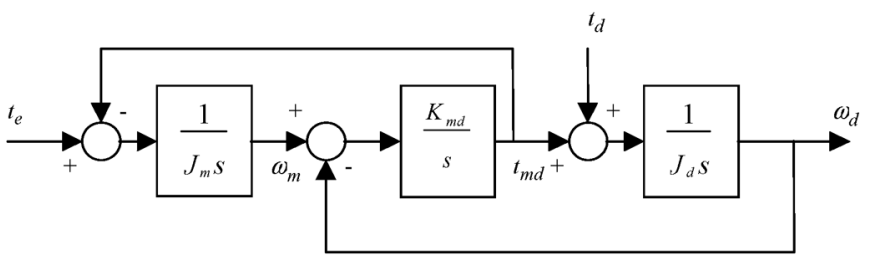

(b)

Fig. 2. Mechanical schematic. (a) Two-inertia representation of a servo-drive system. (b) Control block diagram.

high sensitivity and bandwidth, and are largely unaffected by electromagnetic noise. They can be directly integrated into an electrical machine assembly without significantly affecting the mechanical stiffness of the motor shaft. For the study, SAW devices and RF modules are mounted inside a commercial offthe-shelf permanent-magnet synchronous machine (PMSM), directly onto the motor shaft between the front bearing and the rotor magnets, as illustrated in Fig. 1. Additionally, Fig. 1(b) shows the prototype PMSM with embedded SAW torque transducer and measurement display/output unit.

Here then, an investigation into improved tuning methodologies for the design of classical control schemes, particularly proportional-integral-derivative (PID) and resonance ratio control (RRC), including the use of disturbance observers, is presented along with an appraisal of their relative attributes when used with appropriate sensing technologies.

\section{General Controller Structure}

Typically, a mechanical motor/load servo-drive system exhibits a fundamental resonant mode of $<300 \mathrm{~Hz}$ [9], which often overlaps with the closed-loop bandwidth imposed by the servo-drive control algorithm. In such cases, the servodrive system can be modeled using a two-inertia approximation [1]-[14], [16], [18], [19]. Fig. 2(a) shows a schematic of a twoinertia servo-drive system consisting of two lumped inertias $J_{m}$ and $J_{d}$, which represent the motor and load, respectively, coupled via a shaft of finite stiffness $K_{m d}$ that is subject to 


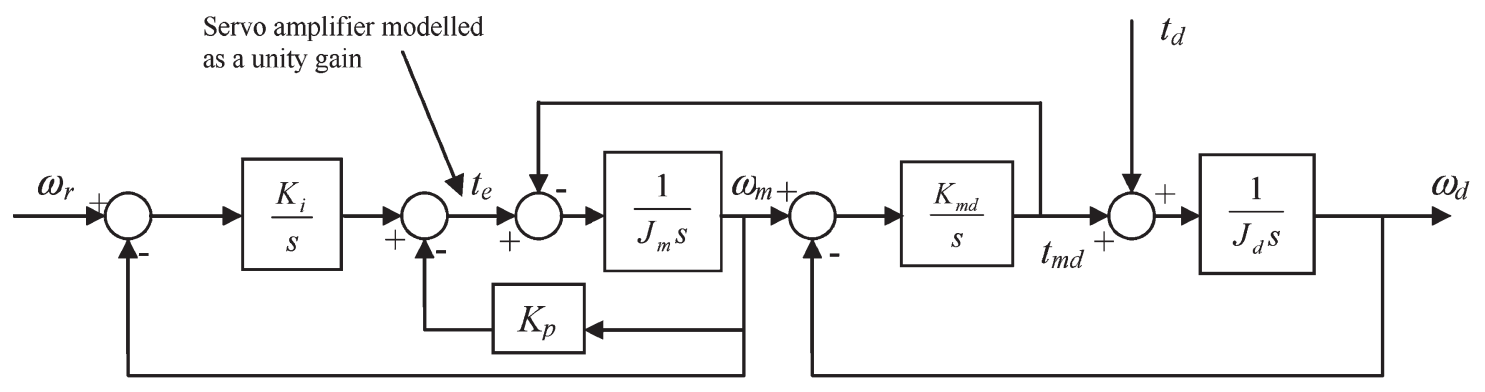

(a)

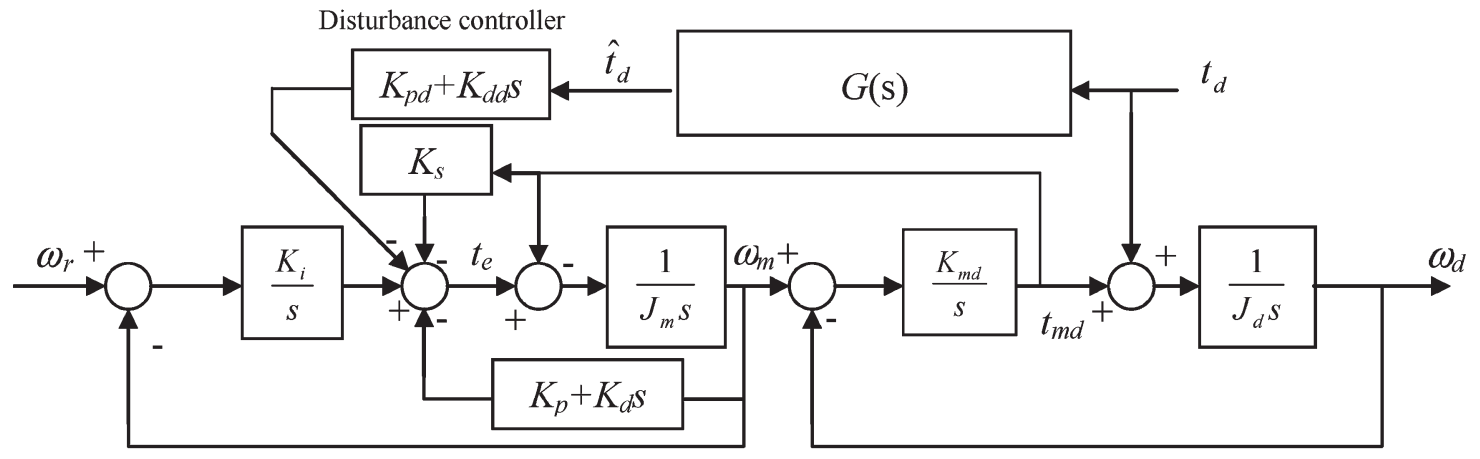

(b)

Fig. 3. Controllers for a two-inertia mechanical model. (a) Classical PI controller. (b) Extended PI controller augmented with feedback of additional state variables.

torsional torque $t_{m d}$ and excited by a combination of electromagnetic torque $t_{e}$ and load torque perturbations $t_{d}$. The motor angular velocity is denoted $\omega_{m}$, and the load velocity is denoted $\omega_{d}$. Since damping losses are usually considered to be relatively low, they are neglected without significantly affecting the accuracy of the forgoing analysis [1]-[14], [16], [18], [19]. Fig. 2(b) shows a dynamic block diagram representation of the system from which transfer functions describing the relationships between the electromagnetic torque produced by the servo machine, and the machine rotor angular velocity (1) and the load angular velocity (2), are obtained as

$$
\begin{aligned}
& \frac{\omega_{m}(s)}{t_{e}(s)}=\frac{s^{2}+\omega_{a}^{2}}{J_{m} s^{3}+J_{m} \omega_{n}^{2} s} \\
& \frac{\omega_{d}(s)}{t_{e}(s)}=\frac{\omega_{a}^{2}}{J_{m} s^{3}+J_{m} \omega_{n}^{2} s}
\end{aligned}
$$

where the antiresonant frequency $\omega_{a}$ and the resonant frequency $\omega_{n}$ are defined as

$$
\begin{aligned}
& \omega_{a}=\sqrt{K_{m d}\left(\frac{1}{J_{d}}\right)} \\
& \omega_{n}=\omega_{a} \sqrt{R+1}
\end{aligned}
$$

and the load-to-motor inertia ratio is

$$
R=\frac{J_{d}}{J_{m}} .
$$

Fig. 3(a) shows a proportional and integral (PI)-type control structure and two-inertia mechanical model. It should be noted that this control structure is equivalent to the classical
PI controller, i.e., the closed-loop poles are identical in both cases. However, for the proposed structure, the closed-loop transfer function from $\omega_{d} / \omega_{r}$ (the tracking response) does not contain closed-loop zeros. This has the advantage of allowing the tracking response to be completely defined by the location of the closed-loop poles. Moreover, the dynamics of the servoamplifier current controller, which are governed primarily by delay time and $-3-\mathrm{dB}$ bandwidth, are assumed to be sufficient to have negligible effect on system response, thereby allowing the servo amplifier to be modeled by a unity gain, as shown in Fig. 3(a). A key limiting factor for raising the dynamic bandwidth of the two-inertia system is, ultimately, the response of the speed loop, which is limited by mechanical resonances and the attributes of the position feedback sensor, by the effects of noise injection (since estimated angular velocity and acceleration are generally obtained from the derivative and double derivative of quantized position) and sensor resonance induced by the physical mounting of the sensor to the motor (not specifically considered herein) [20].

By augmenting the basic controller with the feedback of additional state variables, enhanced disturbance rejection performance can be achieved [1]-[12], [18], [19]. The general structure of such an extended controller is shown in Fig. 3(b), where $G(s)$ is the transfer function describing the relationship between the observed $\hat{t}_{d}$ and the actual load torque $t_{d}$, and $K_{p d}$ and $K_{d d}$ are the associated transfer feedback gains. Furthermore, $K_{s}$ and $K_{d}$ represent the transfer feedback gains associated with shaft torque and the estimated motor acceleration feedback (from second derivative of angular position), respectively. For example, setting $K_{p d}, K_{d d}$, and $K_{d}$ to zero provides a PI controller with shaft torque feedback, referred to as RRC [1]. Alternatively, setting $K_{p d}, K_{d d}$, and $K_{s}$ to zero 
provides a classical PID control scheme [18] (i.e., employed when shaft torque feedback is not available). Notably, the resonant frequency of the experimental mechanical system is $\approx 110 \mathrm{~Hz}$, and the SAW torque sensor and associated electronics exhibit $-3 \mathrm{~dB}>2 \mathrm{kHz}$ [1]. It is therefore assumed that the measured and real shaft torque are identical over the frequency of interest.

Both RRC and PID controller structures can be implemented with the addition of disturbance feedback by setting the disturbance gains $K_{p d}$ and $K_{d d}$ to a nonzero value, i.e., when $K_{p d}=K_{d d}=0$, the disturbance feedback is inactive. By suitable manipulation and assuming that the disturbance torque (as apposed to shaft torque) could be measured with a highbandwidth sensor, i.e., $G(s)=1$

$\frac{\omega_{d}}{t_{d}}=\frac{\left(\widetilde{J}_{m} s^{3}+\left(K_{p}-K_{m d} K_{d d}\right) s^{2}+\left(K_{i}+K_{m d}\left(1-K_{p d}\right) s\right) / J_{d}\right.}{\widetilde{J}_{m} s^{4}+K_{p} s^{3}+\left(\widetilde{J}_{m} \omega_{a}^{2}(1+\widetilde{R})+K_{i}\right) s^{2}+K_{p} \omega_{a}^{2} s+K_{i} \omega_{a}^{2}}$

models the regulation dynamics imposed by the PID controller with measured disturbance feedback, where $\widetilde{J}_{m}=J_{m}+K_{d}$, and $\widetilde{R}=J_{d} / \widetilde{J}_{m}$. Furthermore, (7), which is shown at the bottom of the page, models the regulation dynamics imposed by the RRC controller with measured disturbance feedback, where $\widetilde{J}_{m}=J_{m}$, and $\widetilde{R}=R\left(1+K_{s}\right)$. The numerators of the regulation dynamics describe the assignment of the closed-loop transmission zeros. If, at a particular frequency, the numerator equation is equal to zero, the transmission of a torque perturbation at that frequency is effectively blocked, i.e., completely rejected from the load speed. However, without disturbance feedback, when $K_{p d}=K_{d d}=0$, the assignment of zeros is simultaneously dependent on the assignment of the closed-loop poles by the choice of $K_{p}, K_{i}$, and $K_{d}$ for the PID, and $K_{p}$, $K_{i}$, and $K_{s}$ for the RRC controller. The inclusion of disturbance feedback provides sufficient flexibility to independently assign the closed-loop zeros in the regulation dynamics without affecting the location of the closed-loop poles, since $K_{p d}$ and $K_{d d}$ only appear in the numerator of (6) and (7). By adjusting these gains, a pair of complex conjugate zeros are assigned to the imaginary axis (no damping) for a user-defined frequency $\omega_{r j}$, thereby rejecting periodic load-side disturbances at that frequency.

The required disturbance torque gains for both PID and RRC controllers are given by

$$
\begin{aligned}
K_{p d} & =\frac{K_{m d}\left(1+K_{s}\right)-\omega_{r j}^{2} \widetilde{J}_{m}+K_{i}}{K_{m d}} \\
K_{d d} & =\frac{K_{p}}{K_{m d}}
\end{aligned}
$$

TABLE I

PID AND RRC CONTROLLER GAINS FOR OPTIMAL LOAD-SIDE Tracking Performance

\begin{tabular}{c|c}
\hline PID & RRC \\
\hline$K_{p} \approx 1.85 \omega_{a} J_{d}$ & $K_{p} \approx 1.85 \omega_{a} J_{m}$ \\
$K_{i} \approx 0.6 \omega_{a}^{2} J_{d}$ & $K_{i} \approx 0.6 \omega_{a}^{2} J_{m}$ \\
$K_{d}=J_{d}-J_{m}$ & $K_{s}=\frac{J_{m}}{J_{d}}-1$ \\
\hline
\end{tabular}

where $K_{s}=0$ and $\widetilde{J}_{m}=J_{m}+K_{d}$ for the PID controller, and $\widetilde{J}_{m}=J_{m}$ for the RRC controller.

The closed-loop poles in (6) and (7) cannot be freely assigned since there are only three adjustable control parameters to change the four poles of the closed-loop denominator. However, good damping performance and closed-loop bandwidth can be achieved [1] by assigning the closed-loop poles according to the coefficients of the optimal fourth-order polynomial, as defined by the integral of time multiplied by absolute error (ITAE) performance index using the gains in Table I [1].

\section{EXTEnded ObSERVER-BASEd Control Structures}

\section{A. Practical Disturbance Observer}

For systems subject to periodic disturbances that cannot be directly sensed, the extended control schemes in Fig. 3(b) can be employed based on observer structures. Assuming the disturbance torque to be a state variable that is slowly time varying, implying that $d t_{d} / d t \rightarrow 0$, a simple augmented state can be used to model the disturbance that is subsequently estimated by the observer, i.e.,

$$
\frac{d}{d t}\left[\begin{array}{c}
\omega_{m} \\
\frac{t_{m d}}{t_{-d}} \\
\omega_{d} \\
t_{d}
\end{array}\right]=\left[\begin{array}{c:c:cc}
0 & -\frac{1}{J_{m}} & 0 & 0 \\
\hdashline K_{m d} & 0 & K_{m d} & 0 \\
\hdashline 0 & \frac{1}{J_{d}} & 0 & -\frac{1}{J_{d}} \\
0 & 0 & 0 & 0
\end{array}\right] \cdot\left[\begin{array}{c}
\omega_{m} \\
\frac{t_{m d}}{\frac{T_{d-}}{\omega_{d}}} \\
t_{d}
\end{array}\right]+\left[\begin{array}{c}
\frac{1}{J_{m}} \\
\hdashline 0 \\
\hdashline 0 \\
0
\end{array}\right] t_{e}
$$

Although many techniques can be used to assign the stateerror convergence dynamics, the method attributed to Gopinath [5], [21] is employed here for simplicity. The state vector is partitioned into two parts, i.e.,

$$
\left[\begin{array}{c}
\dot{x}_{m} \\
\hline \dot{x}_{e}
\end{array}\right]=\left[\begin{array}{l|l}
A_{11} & A_{12} \\
\hline A_{21} & A_{22}
\end{array}\right] \cdot\left[\frac{x_{m}}{x_{e}}\right]+\left[\frac{B_{1}}{B_{2}}\right] u
$$

$$
\frac{\omega_{d}}{t_{d}}=\frac{\left(J_{m} s^{3}+\left(K_{p}-K_{m d} K_{d d}\right) s^{2}+\left(K_{i}+K_{m d}\left(1+K_{s}-K_{p d}\right)\right) s\right) / J_{d}}{J_{m} s^{4}+K_{p} s^{3}+\left(J_{m} \omega_{a}^{2}(1+\tilde{R})+K_{i}\right) s^{2}+K_{p} \omega_{a}^{2} s+K_{i} \omega_{a}^{2}}
$$




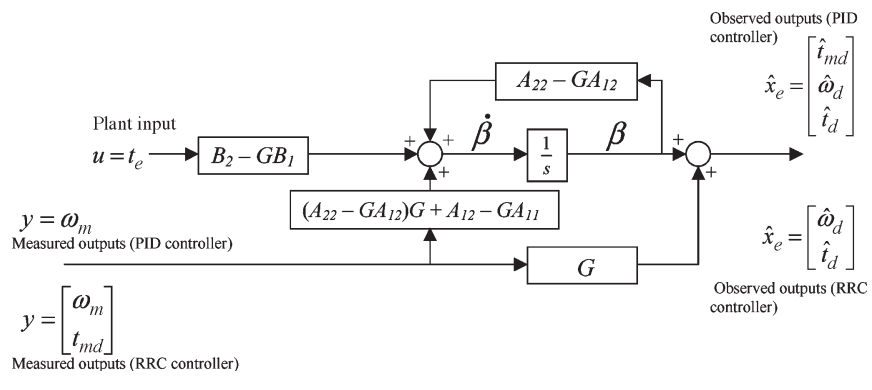

Fig. 4. Block diagram representation of the observer structure.

where $x_{m}$ represents directly measured states, i.e., $x_{m}=y$, where $y$ is the vector of measurable plant outputs, and $x_{e}$ represents the remaining states that need to be observed. In the case of the PID controller, only the motor speed $\omega_{m}$ is sensed, and the required partitions are represented by dotted lines in (10). For the RRC controller, both $\omega_{m}$ and $t_{m d}$ are sensed, and the partitions are represented as dashed lines in (10). Letting $\beta=\hat{x}_{e}-G x_{m}$ (where $\hat{x}_{e}$ represents the observed states), and $G$ is the observer gain matrix, the following is obtained from Gopinath's reduced-order theorem:

$$
\begin{aligned}
\dot{\beta} & =x_{e}\left(A_{22}-G A_{12}\right)+x_{m}\left(A_{21}-G A_{11}\right)+\left(B_{2}-G B_{1}\right) u \\
\hat{x}_{e} & =\beta+G x_{m} .
\end{aligned}
$$

Hence, the PID controller requires a third-order observer, and the RRC controller only requires a second-order observer. For completeness, the dynamic structure of the observer is illustrated in Fig. 4, which shows all the observed output states. Of particular note is that neither the observed load speed $\hat{\omega}_{d}$ nor the shaft torque $\hat{t}_{m d}$ is employed by the proposed controllers. Although not specifically considered herein, the RRC controller with disturbance feedback is realized without a shaft torque sensor by augmenting the controller with a third-order observer and utilizing $\hat{t}_{m d}$. This, however, often results in controller instability as a result of noise injection, since two observed feedback signals are utilized by the controller. Additionally, if either the PID or the RRC controller is augmented with additional $\hat{\omega}_{d}$ feedback, the closed-loop poles can be freely assigned since this results in full state variable feedback. However, good closed-loop damping is achievable with the proposed PID and RRC controllers without the additional feedback of $\hat{\omega}_{d}$, which ultimately complicates system tuning and injects additional controller noise, leading to potential instability and poor closedloop performance.

The transfer function $G(s)$ in Fig. 3(b) that describes the relationship between the observed $\hat{t}_{d}$ and the actual load torque $t_{d}$ can be obtained from (12) [20] for the PID controller

$$
\frac{\hat{t}_{d}(s)}{t_{d}(s)}=\frac{-G_{3} \omega_{a}^{2}}{J_{m} s^{3}-s^{2} G_{1}+s\left(\omega_{a}^{2} J_{m}+G_{2} K_{m d}\right)-G_{3} \omega_{a}^{2}}
$$

and the RRC controller

$$
\frac{\hat{t}_{d}(s)}{t_{d}(s)}=\frac{G_{2} \omega_{a}^{2}}{s^{2}-s G_{1} K_{m d}+G_{2} \omega_{a}^{2}}
$$

TABLE II

Disturbance OBSERVER GAINS

\begin{tabular}{l|c}
\hline $\begin{array}{c}\text { FULL-ORDER (PID } \\
\text { CONTROLLER) }\end{array}$ & $\begin{array}{c}\text { REDUCED-ORDER (RRC } \\
\text { CONTROLLER) }\end{array}$ \\
\hline$G_{1}=-1.75 \omega_{o b} J_{m}$ & $G_{1}=\frac{-1.4 \omega_{o b}}{K_{m d}}$ \\
$G_{2}=\frac{\left(2.15 \omega_{o b}{ }^{2}-\omega_{a}^{2}\right) J_{m}}{K_{m d}}$ & $G_{2}=\frac{\omega_{o b}{ }^{2}}{\omega_{a}^{2}}$ \\
$G_{3}=\frac{-\omega_{o b}{ }^{3} J_{m}}{\omega_{a}^{2}}$ & \\
&
\end{tabular}

respectively, where the denominator equations describe the observer pole locations. The observer poles are now assigned according to the coefficients of the optimal second- and thirdorder ITAE polynomials by the observer gains given in Table II, where $\omega_{\mathrm{ob}}$ is the equivalent $-3-\mathrm{dB}$ observer bandwidth.

If the observer bandwidth (and therefore the observer poles) is (are) assigned to be much greater than the closed-loop zeros in (6) and (7), it can be assumed that the observer dynamics do not unduly influence the performance of the closed-loop regulation dynamics, i.e., the complex zeros do not significantly move from their assigned location. However, in practice, the observer poles cannot be placed significantly higher since there exists a tradeoff between the bandwidth of the observer and the filtering of high-frequency noise. Moreover, in the case of the proposed control scheme, where the derivative of observed load torque is injected directly into the controller output [see Fig. 3(b)], the attenuation of high-frequency noise is of greater importance if the control scheme is to be practically realizable. To examine the additional noise-amplifying attributes imparted by the observer structure, the transfer function from the sensed motor speed $\omega_{m}$ to the observed disturbance torque $\hat{t}_{d}$ is derived for the full-order observer as employed with the PID controller

$$
{\frac{\hat{t}_{d}(s)}{\omega_{m}(s)}}^{\text {full }}=\frac{J_{m} G_{3} s\left(s^{2}+\omega_{a}^{2}(1+R)\right)}{J_{m} s^{3}-s^{2} G_{1}+s\left(\omega_{a}^{2} J_{m}+G_{2} K_{m d}\right)-G_{3} \omega_{a}^{2}}
$$

and the reduced-order observer employed with the RRC controller

$$
{\frac{\hat{t}_{d}(s)}{\omega_{m}(s)}}^{\text {reduced }}=\frac{-G_{2} K_{m d} s}{s^{2}-s G_{1} K_{m d}+G_{2} \omega_{a}^{2}} .
$$

From (15) and (16), it can be seen that $\lim _{s \rightarrow \infty} \mid\left(\hat{t}_{d}(s) \mid\right.$ $\left.\omega_{m}(s)\right)^{\text {full }}|=| G_{3} \mid$ and $\lim _{s \rightarrow \infty}\left|\left(\hat{t}_{d}(s) / \omega_{m}(s)\right)^{\text {reduced }}\right|=0$, i.e., at high frequencies, the full-order observer does not attenuate the high-frequency spectra imposed on motor speed sensor feedback, while the reduced-order observer imparts attenuation at the rate of $-20 \mathrm{~dB} / \mathrm{dec}$, thereby significantly attenuating the noise contribution from the speed signal. Furthermore, the PID controller also requires a contribution of estimated motor acceleration feedback (obtained from the second derivative of motor angular position), thereby further increasing the level of controller-induced noise. 
Nevertheless, the reduced-order observer is also subjected to a noise injection from the torque transducer, as described by the transfer function from the sensed shaft torque $t_{m d}$, to the observed disturbance torque $\hat{t}_{d}$ given by

$$
{\frac{\hat{t}_{d}(s)}{t_{m d}(s)}}^{\text {reduced }}=\frac{G_{2}\left(s^{2}+\omega_{a}^{2}\right)}{s^{2}-s G_{1} K_{m d}+G_{2} \omega_{a}^{2}}
$$

where it can be seen that $\lim _{s \rightarrow \infty}\left|\left(\hat{t}_{d}(s) / t_{m d}(s)\right)^{\text {reduced }}\right|=$ $\left|G_{2}\right|$, i.e., at high frequencies, the reduced-order observer cannot attenuate high-frequency noise on shaft torque feedback. However, if the shaft torque is measured directly and exhibits a good signal-to-noise ratio [1], its noise contribution is considered small when compared with that of the speed signal. It is therefore expected that the RRC controller will exhibit improved noise immunity (and therefore improved robustness due to increased attenuation of high-frequency unmodeled dynamics) compared to the PID counterpart.

\section{B. Controllers With Observed Disturbance Feedback}

Consider the case when $G(s)$, which is the transfer function describing the relationship between the observed $\hat{t}_{d}$ and the actual load torque given by (13) and (14), is included in the disturbance feedback. Equations (18) and (19), which are shown at the bottom of the page, provide the modified closed-loop transfer functions describing the regulation dynamics for the PID and RRC controllers with observed disturbance feedback, respectively. For the PID case (18), it can be seen that the numerator is fifth order (excluding the $s / J_{d}$ multiplier term) and comprises one real and two pairs of complex zeros that can be assigned by the selection of the observer bandwidth $\omega_{\text {ob }}$ and the disturbance feedback gains $K_{p d}$ and $K_{d d}$. Similarly, for the RRC case (19), the numerator is fourth order and comprises two pairs of complex zeros that can be independently assigned. Hence, in each case, by proper adjustment of the gains, the closed-loop system dynamics can be tuned to reject a specific user-defined frequency while eliminating the effects of observer dynamics on rejection performance, i.e., a relatively slow disturbance observer can be realized that attenuates highfrequency noise, without sacrificing the primary control objective of attenuating a periodic disturbance from the load-side velocity profile.

The following equation is a fifth-order polynomial factored into two parts:

$$
\begin{array}{r}
\left(s^{2}+\omega_{r j}^{2}\right)\left(s^{3}+a s^{2}+b s+c\right)=s^{5}+s^{4} a+s^{3}\left(b+\omega_{r j}\right) \\
+s^{2}\left(c+\omega_{r j}^{2} a\right)+s b \omega_{r j}^{2}+c \omega_{r j}^{2}
\end{array}
$$

The first, which is a complex root, represents the user-defined rejection frequency $\omega_{r j}$, where the damping ratio equals zero. The second factor, which is a third-order polynomial, defines the arbitrary location of the other roots.

Equating the numerator of (18) with the expanded polynomial in (20), expressions for the disturbance feedback gains $K_{p d}$ and $K_{d d}$ can be derived for the PID controller that enables $\omega_{r j}$ and the observer bandwidth to be independently assigned, as shown in (21) and (22) at the bottom of the page.

In a similar manner, for the RRC controller, the numerator of (19) is equated to a factorized fourth-order polynomial

$$
\begin{aligned}
\left(s^{2}+\omega_{r j}^{2}\right) & \left(s^{2}+b s+c\right) \\
& =s^{4}+s^{3} b+s^{2}\left(c+\omega_{r j}^{2}\right)+s \omega_{r j}^{2} b+c \omega_{r j}^{2}
\end{aligned}
$$

which gives the resulting disturbance feedback gains in (24) and (25) at the bottom of the next page.

$$
\begin{aligned}
& \frac{\omega_{d}}{t_{d}}=\frac{s}{J_{d}} \frac{\left\{\begin{array}{l}
\widetilde{J}_{m} s^{5}+\left(K_{p}+1.75 \omega_{\mathrm{ob}} \widetilde{J}_{m}\right) s^{4}+\left(2.15 \omega_{\mathrm{ob}}^{2} \widetilde{J}_{m}+1.75 \omega_{\mathrm{ob}} K_{p}+K_{i}+K_{m d}\right) s^{3} \\
+\left(2.15 \omega_{\mathrm{ob}}^{2} K_{p}+\omega_{\mathrm{ob}}^{3} \widetilde{J}_{m}+1.75 \omega_{\mathrm{ob}}\left[K_{i}+K_{m d}\right]\right) s^{2} \\
+\left(\omega_{\mathrm{ob}}^{3} K_{p}+2.15 \omega_{\mathrm{ob}}^{2}\left[K_{i}+K_{m d}\right]-J_{d} K_{d d} \omega_{\mathrm{ob}}^{3} \omega_{a}^{2}\right) s+\omega_{\mathrm{ob}}^{3}\left[K_{i}+K_{m d}\right]-J_{d} K_{p d} \omega_{\mathrm{ob}}^{3} \omega_{a}^{2}
\end{array}\right\}}{\left.\left(\widetilde{J}_{m} s^{4}+K_{p} s^{3}+\left(\widetilde{J}_{m} \omega_{a}^{2}(1+\widetilde{R})+K_{i}\right) s^{2}+K_{p} \omega_{a}^{2} s+K_{i} \omega_{a}^{2}\right) \cdot\left(s^{3}+1.75 \omega_{\mathrm{ob}} s^{2}+2.15 \omega_{\mathrm{ob}}^{2} s+\omega_{\mathrm{ob}}^{3}\right)\right\}} \\
& \frac{\omega_{d}}{t_{d}}=\frac{s}{J_{d}} \frac{\left\{\begin{array}{l}
J_{m} s^{4}+\left(K_{p}+1.4 \omega_{\mathrm{ob}} J_{m}\right) s^{3}+\left(\omega_{\mathrm{ob}}^{2} J_{m}+1.4 \omega_{\mathrm{ob}} K_{p}+\left[K_{i}+K_{m d}\left(1+K_{s}\right)\right]\right) s^{2} \\
+\left(\omega_{\mathrm{ob}}^{2} K_{p}+1.4 \omega_{\mathrm{ob}}\left[K_{i}+K_{m d}\left(1+K_{s}\right)\right]-J_{d} K_{d d} \omega_{\mathrm{ob}}^{2} \omega_{a}^{2}\right) s+\omega_{\mathrm{ob}}^{2}\left[K_{i}+K_{m d}\left(1+K_{s}\right)\right]-J_{d} K_{p d} \omega_{\mathrm{ob}}^{2} \omega_{a}^{2}
\end{array}\right\}}{\left\{\left(J_{m} s^{4}+K_{p} s^{3}+\left(J_{m} \omega_{a}^{2}(1+\widetilde{R})+K_{i}\right) s^{2}+K_{p} \omega_{a}^{2} s+K_{i} \omega_{a}^{2}\right) \cdot\left(s^{2}+1.4 \omega_{\mathrm{ob}} s+\omega_{\mathrm{ob}}^{2}\right)\right\}}
\end{aligned}
$$

$$
\begin{aligned}
K_{p d}= & \frac{\omega_{\mathrm{ob}}^{3}\left(K_{i}+K_{m d}\right)-\omega_{r j}^{2}\left(\widetilde{J}_{m} \omega_{\mathrm{ob}}^{3}+2.15 \omega_{\mathrm{ob}}^{2} K_{p}+1.75 \omega_{\mathrm{ob}}\left(K_{i}+K_{m d}\right)-\omega_{r j}^{2}\left(\widetilde{J}_{m} \omega_{\mathrm{ob}} 1.75+K_{p}\right)\right)}{J_{d} \omega_{\mathrm{ob}}^{3} \omega_{a}^{2}} \\
K_{d d} & =\frac{\omega_{\mathrm{ob}}^{3} K_{p}+2.15 \omega_{\mathrm{ob}}^{2}\left(K_{i}+K_{m d}\right)-\omega_{r j}^{2}\left(\widetilde{J}_{m} 2.15 \omega_{\mathrm{ob}}^{2}+1.75 \omega_{\mathrm{ob}} K_{p}+K_{i}+K_{m d}-\omega_{r j}^{2} \widetilde{J}_{m}\right)}{J_{d} \omega_{\mathrm{ob}}^{3} \omega_{a}^{2}}
\end{aligned}
$$


TABLE III

Mechanical Parameters

\begin{tabular}{l|l}
\hline$R$ & 0.5 \\
$J_{d}$ & $0.00025 \mathrm{kgm}^{2}$ \\
$K_{m d}$ & $80 \mathrm{Nm} / \mathrm{rad}$ \\
$\omega_{a}$ & $565.7 \mathrm{rad} / \mathrm{s} \quad(90 \mathrm{~Hz})$ \\
\hline
\end{tabular}

\section{Regulation FREQUenCy Response}

A two-inertia test facility consisting of a $1.1-\mathrm{kW}$ prototype PMSM with integrated SAW torque transducer [see Fig. 1(b)] and a similarly rated commercial PMSM (Control Techniques Ltd. Unidrive SP), representing the motor and load inertias, respectively, is now used for the experimental validation of the presented theoretical principles. The controllers and observers are implemented on a dSpace hardware-in-the-loop development platform. Both machines are excited by identical servo amplifiers (Control Techniques Ltd. Unidrive SP) and interconnected via an additional inline SAW-based torque transducer. The mechanical parameters of the test facility are given in Table III. Using the presented control structures, dynamic simulation models of the experimental closed-loop system are now used to provide performance comparisons. Regulation performance is evaluated via the closed-loop system's ability to reject a sinusoidal load-side disturbance. By way of example, the load-side disturbance is a $3-\mathrm{N} \cdot \mathrm{m} 62.8 \mathrm{-rad} / \mathrm{s}(10-\mathrm{Hz})$ sine wave.

\section{A. Case (i)-Assume an Ideal (High-Bandwidth) Disturbance Observer}

In this case, the dynamics of the observer are of sufficient bandwidth that the designer would normally neglect their influence on the closed-loop system; hence, an ideal infinite bandwidth disturbance torque feedback is assumed. The gains $K_{p d}$ and $K_{d d}$ are therefore chosen according to (8) and (9), where $\omega_{r j}=62.8 \mathrm{rad} / \mathrm{s}$. To illustrate the influence of the observer dynamics (which have been ignored in this case) on the resulting regulation performance, Fig. 5 compares the closed-loop frequency response from disturbance torque $t_{d}$ to load speed $\omega_{d}$ as the observer bandwidth $\omega_{\mathrm{ob}}$ is varied, see Table II. In particular, Fig. 5(a) shows the PID controller that employs the full-order observer, while Fig. 5(b) shows the RRC controller that employs the reduced-order observer. Additionally, for comparison, the regulation performance without disturbance feedback is also shown and is notably identical for both controllers. The results show that both control schemes impart similar attenuation characteristics as $\omega_{\mathrm{ob}}$ is reduced, and

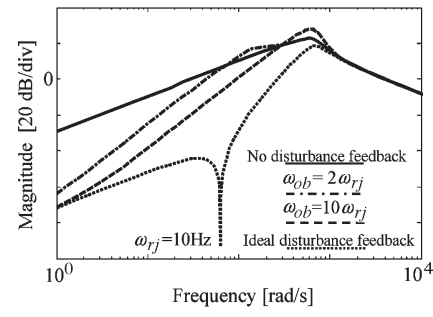

(a)

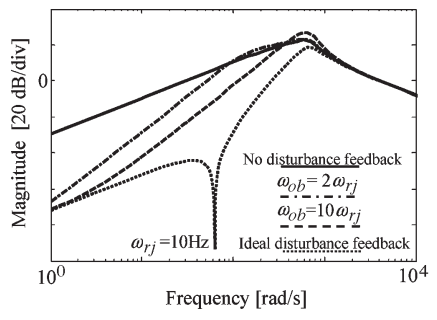

(b)
Fig. 5. Regulation performance when disturbance gains are chosen assuming case (i) as an ideal (infinite bandwidth) observer. (a) PID controller. (b) RRC controller.

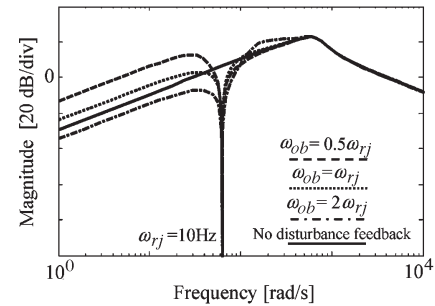

(a)

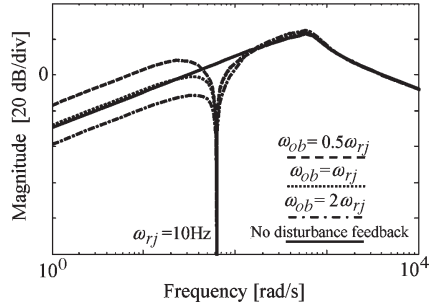

(b)
Fig. 6. Regulation performance when disturbance gains are chosen assuming case (ii) as a nonideal (finite bandwidth) observer. (a) PID controller. (b) RRC controller.

in both cases, the dynamics attributed to the observer unduly influences the ability of the closed-loop system to attenuate $\omega_{r j}$, even when relatively high-bandwidth observers are employed. Nevertheless, it can be seen that, in general, the low-frequency disturbance rejection performance is improved with the implementation of disturbance feedback.

\section{B. Case (ii)—Assume a Nonideal Disturbance Observer}

In this case, the disturbance torque feedback is assumed to be nonideal, and the dynamics of the disturbance observer are included in the tuning procedure. The disturbance gains are chosen according to (21) and (22) for the PID controller and to (24) and (25) for the RRC controller, where again $\omega_{r j}=$ $62.8 \mathrm{rad} / \mathrm{s}$. Fig. 6(a) and (b) shows the regulation frequency response for the PID and RRC controllers, respectively, as $\omega_{\text {ob }}$ is varied. It can be seen that, for both controllers, reducing the bandwidth of the observer does not significantly influence the control objective, i.e., the attenuation at $\omega_{r j}$ remains constant. However, a relatively low-bandwidth observer, in general, reduces the attenuation at low frequencies, i.e., when $\omega<$ $\omega_{r j}$, as shown in Fig. 6(a) and (b). Furthermore, when the observer bandwidth approaches, or is less than, the desired rejection frequency, low-frequency disturbances are amplified when compared with the case with no disturbance feedback.

$$
\begin{aligned}
K_{p d} & =\frac{\omega_{\mathrm{ob}}^{2}\left(K_{i}+K_{m d}\left(1+K_{s}\right)\right)-\omega_{r j}^{2}\left(\omega_{\mathrm{ob}}^{2} J_{m}+1.4 \omega_{\mathrm{ob}} K_{p}+K_{i}+K_{m d}\left(1+K_{s}\right)-\omega_{r j}^{2} J_{m}\right)}{J_{d} \omega_{\mathrm{ob}}^{2} \omega_{a}^{2}} \\
K_{d d} & =\frac{\omega_{\mathrm{ob}}^{2} K_{p}+1.4 \omega_{\mathrm{ob}}\left(K_{i}+K_{m d}\left(1+K_{s}\right)\right)-\omega_{r j}^{2}\left(K_{p}+1.4 \omega_{\mathrm{ob}} J_{m}\right)}{J_{d} \omega_{\mathrm{ob}}^{2} \omega_{a}^{2}}
\end{aligned}
$$




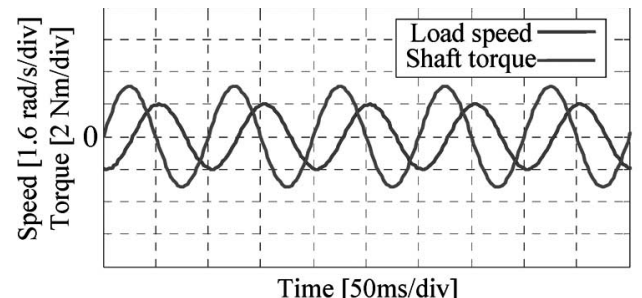

(a)

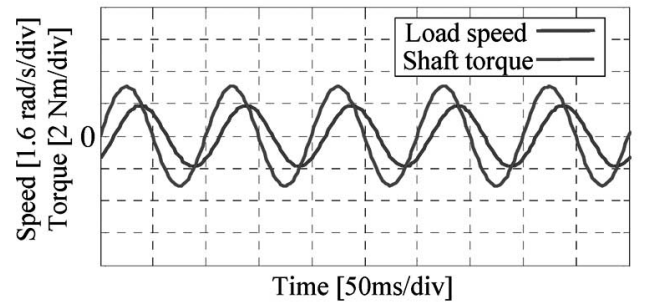

(b)

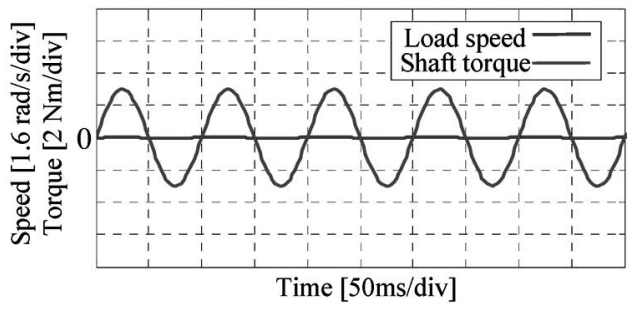

(c)

Fig. 7. PID controller. (a) No disturbance feedback. (b) Disturbance feedback, case (i), $\omega_{\mathrm{ob}}=2 \omega_{r j}$. (c) Disturbance feedback, case (ii), $\omega_{\mathrm{ob}}=2 \omega_{r j}$.

It is therefore desirable to employ an observer of sufficient bandwidth to ensure adequate rejection of the low-frequency band, particularly in the event of a variation in the disturbance frequency. Moreover, it can be seen that, in general, the RRC controller improves the low-frequency attenuation for a given observer bandwidth when compared with the performance of the PID controller.

Fig. 7 shows an example time-domain response imparted by the PID controller when subjected to a sinusoidal load-side disturbance of $3 \mathrm{~N} \cdot \mathrm{m}$ and $62.8 \mathrm{rad} / \mathrm{s}(10 \mathrm{~Hz})$, which shows both the load speed $\omega_{d}$ and the shaft torque $t_{m d}$. In particular, Fig. 7(a) shows the response with no disturbance feedback, and Fig. 7(b) and (c) shows the response with disturbance feedback for cases (i) and (ii), respectively, where, in both cases, $\omega_{\mathrm{ob}}=2 \omega_{r j}$. It can be seen that significant improvement of the regulation performance is obtained in case (ii) [Fig. 7(c)], where load perturbations are almost completely rejected from the load speed, compared with case (i) [Fig. 7(b)], where only a small attenuation of the load perturbation is evident.

\section{EXPERIMENTAL RESULTS}

The experimental results now presented are in response to a $3-\mathrm{N} \cdot \mathrm{m}$ sinusoidal disturbance torque with a frequency of $62.8 \mathrm{rad} / \mathrm{s}(10 \mathrm{~Hz})$, where the speed controller reference is chosen to be constant at $10 \mathrm{rad} / \mathrm{s}$. For all the results, shaft torque measurements are obtained from the integrated torque transducer [17]. Fig. 8 shows the time-domain regulation performance imparted by the PID controller for case (i) as

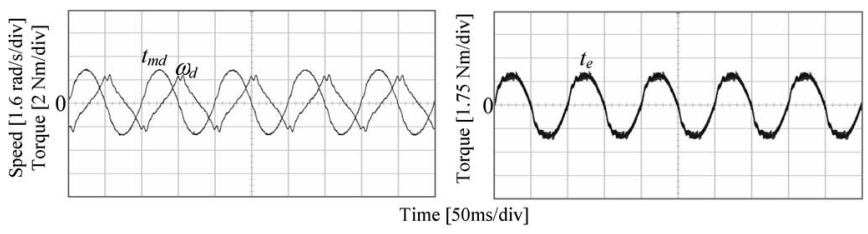

(a)

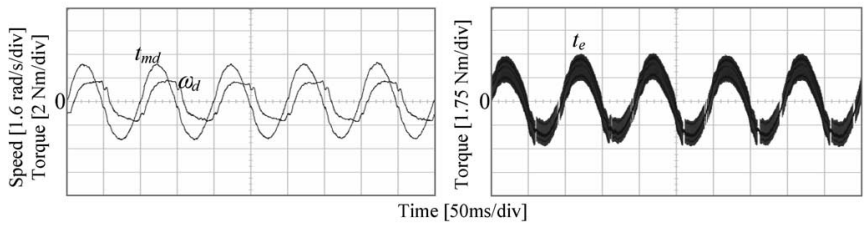

(b)

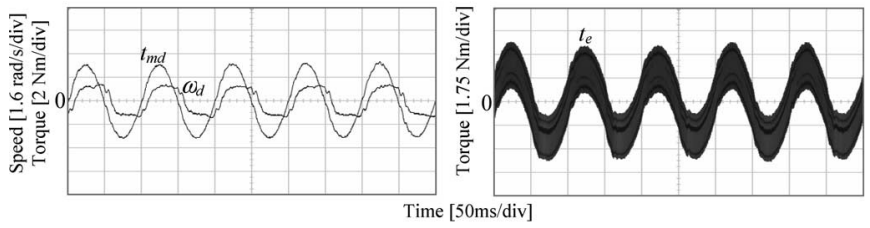

(c)

Fig. 8. PID controller tuned assuming ideal disturbance observer (a) No disturbance feedback. (b) Disturbance feedback, case (i), $\omega_{\mathrm{ob}}=2 \omega_{r j}$. (c) Disturbance feedback, case (i), $\omega_{\mathrm{ob}}=2.5 \omega_{r j}$.

the observer bandwidth is increased. The controller output $t_{e}$ (which is assumed to be electromagnetic torque production) is also shown to demonstrate the levels of controller noise. Specifically, Fig. 8(a) shows the response with no disturbance feedback, and Fig. 8(b) and (c) shows the response with disturbance feedback for $\omega_{\mathrm{ob}}=2 \omega_{r j}$ and $2.5 \omega_{r j}$, respectively. Notably, Fig. 8(a) and (b) depicts the same events used in the simulation results of Fig. 7(a) and (b), respectively. From Fig. 8, therefore, it can be seen that increasing the observer bandwidth $\omega_{\text {ob }}$ significantly increases the controller-induced noise with only a small improvement in disturbance attenuation.

Fig. 9 shows the PID controller responses for case (ii) as the observer bandwidth is increased, where $\omega_{\mathrm{ob}}=0.5 \omega_{r j}, \omega_{r j}$, and $1.25 \omega_{r j}$, respectively. It can be seen that load perturbations are rejected from the load speed, and rejection performance is not unduly influenced by the bandwidth of the observer. Furthermore, when the observer bandwidth is less than the rejection frequency [Fig. 9(a)], i.e., when $\omega_{\mathrm{ob}}=0.5 \omega_{r j}$, the controller noise is attenuated to levels comparable to that obtained with no disturbance feedback [Fig. 8(a)].

Of note is that when $\omega_{\mathrm{ob}}>1.5 \omega_{r j}(>15 \mathrm{~Hz})$, instability occurs when using the PID controller [for case (ii)] due to the excitation of high-order dynamics by elevated noise levels. By comparison, the RRC controller can employ an observer of much higher bandwidth before instability occurs, when $\omega_{\text {ob }}>$ $3.5 \omega_{r j}(>35 \mathrm{~Hz})$, by virtue of the reduced noise levels. By way of example, Fig. 10 shows the responses of the RRC controller for $\omega_{\mathrm{ob}}=2.5 \omega_{r j}$, i.e., when the torque feedback is derived from the integrated torque transducer (within the case of the motor) [Fig. 10(a)] and the conventional inline instrument transducer (coupled between motor and load machines) [Fig. 10(b)], respectively. It can be seen that the use of the integrated or inline transducer results in near-identical responses, thereby demonstrating their equivalent dynamic capability. 


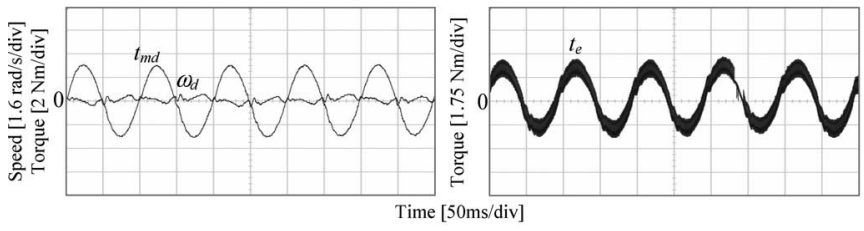

(a)

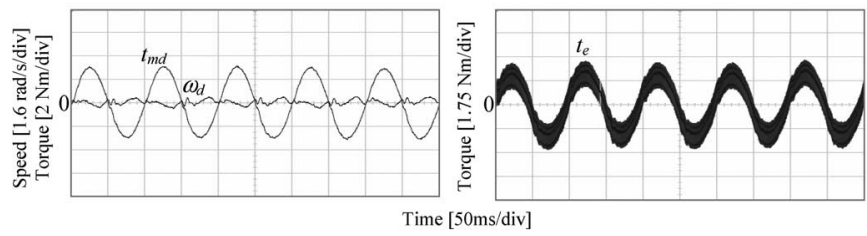

(b)

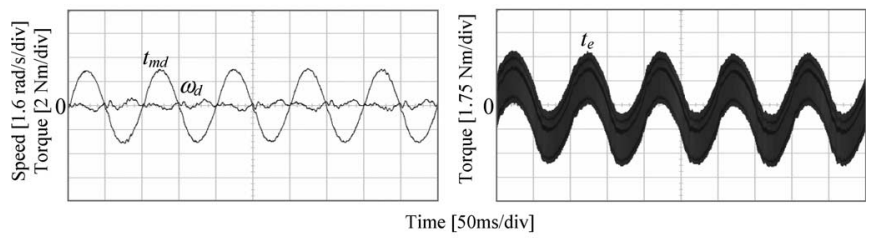

(c)

Fig. 9. PID controller tuned assuming nonideal disturbance observer. (a) Disturbance feedback, case (ii), $\omega_{\mathrm{ob}}=0.5 \omega_{r j}$. (b) Disturbance feedback, case (ii), $\omega_{\mathrm{ob}}=\omega_{r j}$. (c) Disturbance feedback, case (ii), $\omega_{\mathrm{ob}}=1.25 \omega_{r j}$.

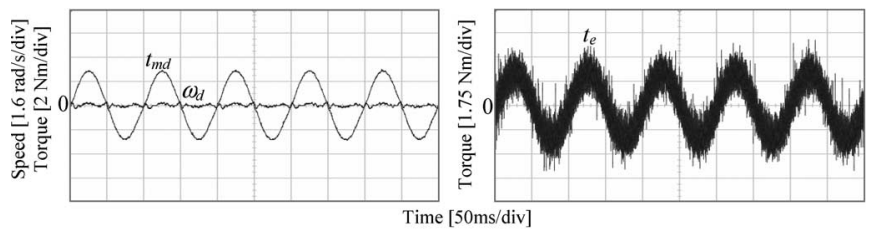

(a)

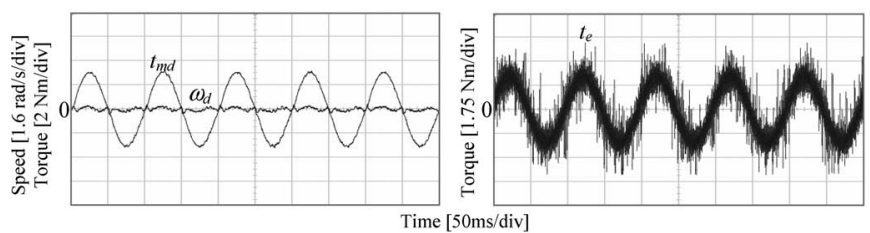

(b)

Fig. 10. RRC controller tuned assuming nonideal disturbance observer. (a) Disturbance feedback, case (ii) (integrated transducer), $\omega_{\mathrm{ob}}=2.5 \omega_{r j}$. (b) Disturbance feedback, case (ii) (inline transducer), $\omega_{\mathrm{ob}}=2.5 \omega_{r j}$.

Furthermore, Figs. 9 and 10 demonstrate the equivalence of the PID and RRC controllers with observer disturbance feedback. However, by virtue of increased observer bandwidth and improved rejection performance [compare Fig. 6(a) and (b)], the RRC controller, in general, imparts improved disturbance rejection over the low-frequency band, which results in "flatter" unperturbed load speed traces. By way of a further example, Fig. 11 compares the responses of the PID and RRC controllers with a $30 \%$ reduction in the frequency of the load perturbation (from 10 to $6.5 \mathrm{~Hz}$ ). It can be seen that the RRC controller [Fig. 11(c)] almost completely rejects the lowfrequency perturbations from the load speed compared with the PID controller [Fig. 11(b)], where only a small attenuation of the load perturbations is evident, when compared with no disturbance feedback [Fig. 11(a)]. These results demonstrate the requirement of a higher bandwidth observer to generally

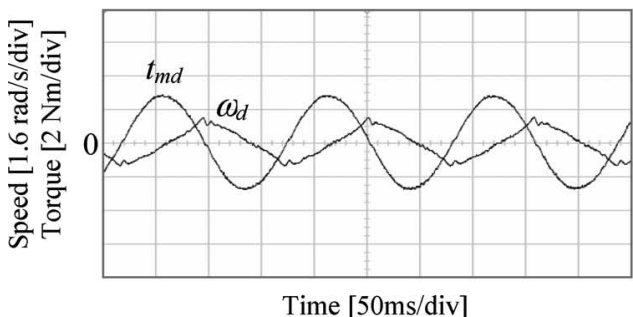

(a)

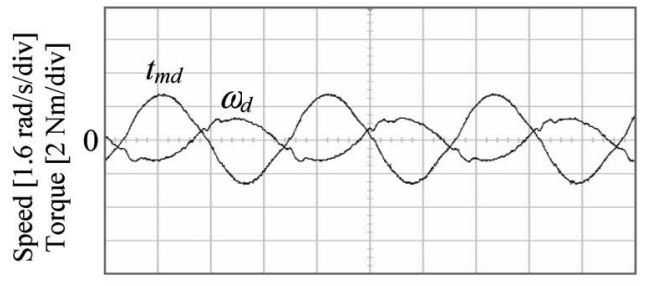

Time $[50 \mathrm{~ms} / \mathrm{div}]$

(b)

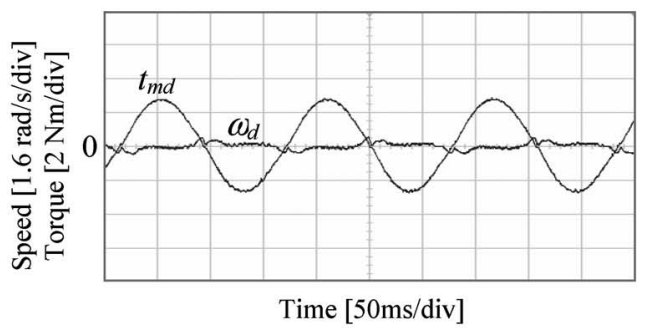

(c)

Fig. 11. Controllers tuned assuming nonideal disturbance observer with $30 \%$ reduction in frequency of disturbance perturbation. (a) No disturbance feedback. (b) Disturbance feedback, case (ii), PID controller, $\omega_{\mathrm{ob}}=\omega_{r j}$. (c) Disturbance feedback, case (ii), RRC controller (integrated transducer), $\omega_{\mathrm{ob}}=2.5 \omega_{r j}$.

ensure adequate rejection of low frequencies (see Fig. 6). As previously discussed, this is of particular importance as the frequency of the load perturbation is likely to vary in the field. In such cases, therefore, an RRC controller is again the preferred solution.

It should be noted that to maintain clarity of the presented results, only those of significant importance have been given explicitly in Figs. 7-11. Nevertheless, other results of interest can also be readily obtained from the data presented in Tables I -IV and (13), (14), (21), (22), (24), and (25), for instance.

\section{CONCLUSION}

To address the effects of periodic load-side disturbance torques on the load speed profile, extended controllers, based on classical feedforward compensation, have been proposed. For the investigation, a SAW torque transducer is mounted inside a commercial off-the-shelf PMSM. The extended controllers therefore retain the flexibility afforded by the PID and RRC control schemes [1] to simultaneously impart optimal closed-loop damping by allowing the independent selection of virtual inertia ratio while additionally facilitating the independent assignment of regulation transmission zeros such that, when properly assigned, it enables the rejection of a periodic disturbance torque from the load speed. It is shown 
TABLE IV

Gains EMPloyed By Simulated AND EXPERIMENTAL CONTROLlers

\begin{tabular}{|c|c|c|c|c|c|c|c|c|c|c|}
\hline Figures & $\begin{array}{l}\text { Observer } \\
\text { bandwidth } \\
\omega_{o b}\end{array}$ & $\begin{array}{l}\text { Integral } \\
\text { gain } K_{i}\end{array}$ & $\begin{array}{l}\text { Proportional } \\
\text { gain } K_{p}\end{array}$ & $\begin{array}{l}\text { Derivative } \\
\text { gain } K_{d}\end{array}$ & $\begin{array}{l}\text { Shaft } \\
\text { torque } \\
\text { gain } K_{S}\end{array}$ & $\begin{array}{l}\text { Disturbance } \\
\text { Proportional } \\
\text { gain } K_{p d}\end{array}$ & $\begin{array}{l}\text { Disturbance } \\
\text { Derivative } \\
\text { gain } K_{d d}\end{array}$ & $\begin{array}{l}\text { Observer } \\
\text { gain } G_{I}\end{array}$ & $\begin{array}{l}\text { Observer } \\
\text { gain } G_{2}\end{array}$ & $\begin{array}{l}\text { Observer } \\
\text { gain } G_{3}\end{array}$ \\
\hline \multirow[t]{3}{*}{$5(a)$} & $\begin{array}{l}\text { No } \\
\text { disturbance } \\
\text { feedback }\end{array}$ & 48 & 0.2602 & $-2.5 e-004$ & & & & & & \\
\hline & $2 \omega_{r j}$ & 48 & 0.2602 & $-2.5 \mathrm{e}-004$ & & 1.5877 & 0.0033 & -0.1100 & -1.7878 & -0.0031 \\
\hline & $10 \omega_{r j}$ & 48 & 0.2602 & $-2.5 \mathrm{e}-004$ & & 1.5877 & 0.0033 & -0.5498 & 3.3049 & -0.3876 \\
\hline \multirow[t]{3}{*}{5 (b) } & $\begin{array}{l}\text { No } \\
\text { disturbance } \\
\text { feedback }\end{array}$ & 96 & 0.5204 & & 1.0 & & & & & \\
\hline & $2 \omega_{r j}$ & 96 & 0.5204 & & 1.0 & 3.1753 & 0.0065 & -2.1991 & 0.0493 & \\
\hline & $10 \omega_{r j}$ & 96 & 0.5204 & & 1.0 & 3.1753 & 0.0065 & -10.9956 & 1.2337 & \\
\hline \multirow[t]{4}{*}{ 6(a) } & $\begin{array}{l}\text { No } \\
\text { disturbance } \\
\text { feedback }\end{array}$ & 48 & 0.2602 & $-2.5 \mathrm{e}-004$ & & & & & & \\
\hline & $0.5 \omega_{r j}$ & 48 & 0.2602 & $-2.5 \mathrm{e}-004$ & & -8.7698 & -0.1130 & -0.0275 & -1.9867 & $-4.8447 \mathrm{e}-005$ \\
\hline & $\omega_{r j}$ & 48 & 0.2602 & $-2.5 \mathrm{e}-004$ & & -1.4258 & 0.0266 & -0.0550 & -1.9470 & $-3.8758 \mathrm{e}-004$ \\
\hline & $2 \omega_{r j}$ & 48 & 0.2602 & $-2.5 e-004$ & & 0.6989 & 0.0258 & -0.1100 & -1.7878 & -0.0031 \\
\hline \multirow[t]{4}{*}{$6(b)$} & $\begin{array}{l}\text { No } \\
\text { disturbance } \\
\text { feedback }\end{array}$ & 96 & 0.5204 & & 1.0 & & & & & \\
\hline & $0.5 \omega_{r j}$ & 96 & 0.5204 & & 1.0 & -10.6705 & 0.1220 & -0.5498 & 0.0031 & \\
\hline & $\omega_{r j}$ & 96 & 0.5204 & & 1.0 & -0.5722 & 0.0708 & -1.0996 & 0.0123 & \\
\hline & $2 \omega_{r j}$ & 96 & 0.5204 & & 1.0 & 2.0954 & 0.0403 & -2.1991 & 0.0493 & \\
\hline 7 (a) & $\begin{array}{l}\text { No } \\
\text { disturbance } \\
\text { feedback }\end{array}$ & 48 & 0.2602 & $-2.5 e-004$ & & & & & & \\
\hline $7(b)$ & $2 \omega_{r j}$ & 48 & 0.2602 & $-2.5 e-004$ & & 1.5877 & 0.0033 & -0.1100 & -1.7878 & -0.0031 \\
\hline $7(\mathrm{c})$ & $2 \omega_{r j}$ & 48 & 0.2602 & $-2.5 \mathrm{e}-004$ & & 0.6989 & 0.0258 & -0.1100 & -1.7878 & -0.0031 \\
\hline $8(a)$ & $\begin{array}{l}\text { No } \\
\text { disturbance } \\
\text { feedback }\end{array}$ & 48 & 0.2602 & $-2.5 e-004$ & & & & & & \\
\hline $8(b)$ & $2 \omega_{r j}$ & 48 & 0.2602 & $-2.5 \mathrm{e}-004$ & & 1.5877 & 0.0033 & -0.1100 & -1.7878 & -0.0031 \\
\hline $8(\mathrm{c})$ & $2.5 \omega_{r j}$ & 48 & 0.2602 & $-2.5 \mathrm{e}-004$ & & 1.5877 & 0.0033 & -0.1374 & -1.6684 & -0.0061 \\
\hline 9(a) & $0.5 \omega_{r j}$ & 48 & 0.2602 & $-2.5 \mathrm{e}-004$ & & -8.7698 & -0.1130 & -0.0275 & -1.9867 & $-4.8447 \mathrm{e}-005$ \\
\hline 9(b) & $\omega_{r j}$ & 48 & 0.2602 & $-2.5 \mathrm{e}-004$ & & -1.4258 & 0.0266 & -0.0550 & -1.9470 & $-3.8758 \mathrm{e}-004$ \\
\hline $9(\mathrm{c})$ & $1.25 \omega_{r j}$ & 48 & 0.2602 & $-2.5 \mathrm{e}-004$ & & -0.4374 & 0.0301 & -0.0687 & -1.9171 & $-7.5699 \mathrm{e}-004$ \\
\hline $10(a)$ & $2.5 \omega_{r j}$ & 96 & 0.5204 & & 1.0 & 2.4384 & 0.0338 & -2.7489 & 0.0771 & \\
\hline $10(\mathrm{~b})$ & $2.5 \omega_{r j}$ & 96 & 0.5204 & & 1.0 & 2.4384 & 0.0338 & -2.7489 & 0.0771 & \\
\hline 11(a) & $\begin{array}{l}\text { No } \\
\text { disturbance } \\
\text { feedback }\end{array}$ & 48 & 0.2602 & $-2.5 e-004$ & & & & & & \\
\hline 11(b) & $\omega_{r j}$ & 48 & 0.2602 & $-2.5 e-004$ & & -1.4258 & 0.0266 & -0.0550 & -1.9470 & $-3.8758 \mathrm{e}-004$ \\
\hline $11(\mathrm{c})$ & $2.5 \omega_{r j}$ & 96 & 0.5204 & & 1.0 & 2.4384 & 0.0338 & -2.7489 & 0.0771 & \\
\hline
\end{tabular}


that reducing the bandwidth of the disturbance observer, to suppress noise, adversely affects the performance of the feedforward compensation (since the zeros move away from their assigned location). To address this, appraisal has been given to the combined observer and controller dynamics, with the zeros reassigned, and demonstrating that the bandwidth of the observer need not effect the rejection of a periodic disturbance, thereby enabling significantly lower-bandwidth observers to be employed, i.e., the observer bandwidth can be lower than the rejection frequency.

The equivalence of the PID and RRC controllers with observer disturbance feedback is demonstrated. However, for applications where the frequency of the periodic disturbance is varying, it is shown that higher bandwidth disturbance observers are required to maximize the disturbance attenuation over all of the low-frequency band (as well as the desired rejection frequency), thereby attenuating a wide range of possible frequencies. In such cases, therefore, it is shown that the RRC controller is the preferred solution since it can employ significantly higher observer bandwidths, when compared to PID counterparts, by virtue of reduced noise sensitivity. Furthermore, it is demonstrated that the $20-\mathrm{N} \cdot \mathrm{m}$ SAW torque transducer integrated into the casing of the servo machine, as employed by the RRC controller, is not unduly affected by machine-generated electromagnetic noise and exhibits similar dynamic behavior as the conventional instrument inline torque transducer (coupled between motor and load). Moreover, the replacement of the conventional inline torque transducer in favor of the machine-integrated solution eliminates the requirement of additional transmission couplings and ultimately increases transmission stiffness. Furthermore, the mechanical modifications to the commercial PMSM are minimal, which increases the total machine cost by only a few percent.

Finally, it should be noted that to provide a comparative theoretical analysis of the presented control schemes, this paper is limited to considering only the linear region of system operation. Nevertheless, consideration of nonlinear saturation, for instance, such as electromagnetic torque limits, is ultimately of important practical significance, albeit beyond the scope of this paper. This is currently the subject of further research activity based on nonlinear control techniques and will be reported as an extension to this paper in due course.

\section{REFERENCES}

[1] T. M. O'Sullivan, N. Schofield, and C. M. Bingham, "High-performance control of dual-inertia servo-drive systems using low-cost integrated SAW torque transducers," IEEE Trans. Ind. Electron., vol. 53, no. 4, pp. 1226-1237, Jun. 2006.

[2] G. Ellis, Control System Design Guide. New York: Academic, 2004.

[3] —, Observers in Control Systems: A Practical Guide. New York: Academic, 2002.

[4] J. K. Ji and S. K. Sul, "Kalman filter and LQ based speed controller for torsional vibration suppression in a 2-mass motor drive system," IEEE Trans. Ind. Electron., vol. 42, no. 6, pp. 564-571, Dec. 1995.

[5] Y. Hori, H. Iseki, and K. Sugiura, "Basic consideration of vibration suppression and disturbance rejection control of multi-inertia system using SFLAC (state feedback and load acceleration control)," IEEE Trans. Ind. Appl., vol. 30, no. 4, pp. 889-896, Jul./Aug. 1994.

[6] S. H. Song, J. K. Ji, S. K. Sul, and M. H. Park, "Torsional vibration suppression control in 2-mass system by state feedback speed controller," in Proc. 2nd IEEE CCA, Sep. 1993, vol. 1, pp. 129-134.
[7] G. Ellis, "Cures for mechanical resonance in industrial servo systems," in Proc. PCIM, Jun. 2001, pp. 187-192.

[8] G. Ellis and R. D. Lorenz, "Resonant load control methods for industrial servo drives," in Proc. IEEE IAS Annu. Meeting, Oct. 2000, vol. 3, pp. 1438-1445.

[9] S. N. Vukosavic and M. R. Stojic, "Suppression of torsional oscillations in a high performance speed servo drive," IEEE Trans. Ind. Electron., vol. 45, no. 1, pp. 108-117, Feb. 1998.

[10] J. Keun, J. Dong, C. Lee, and S. K. Sul, "LQG based speed controller for torsional vibration suppression in 2-mass motor drive system," in Proc. IEEE IECON, Nov. 1993, vol. 2, pp. 1157-1162.

[11] J. M. Pacas, A. John, and T. Eutebach, "Automatic identification and damping torsional vibration in high-dynamic drives," in Proc. IEEE ISIE, Dec. 2000, vol. 1, pp. 201-206.

[12] G. Gotting and R. W. De Doncker, "Evaluation of advanced algorithms for suppression-control of drivetrain-oscillations in electric vehicles," in Proc. EVS-18, Oct. 2001, CD-ROM.

[13] T. Orlowska-Kowalska and K. Szabat, "Sensitivity analysis of state variable estimators for two-mass drive system," Acta Electrotech. Inform. vol. 4, no. 1, 2004, CD-ROM.

[14] K. Hong, "A load torque compensation scheme under the speed measurement delay," IEEE Trans. Ind. Electron., vol. 45, no. 2, pp. 283-290, Apr. 1998.

[15] S.-M. Yang and S.-J. Ke, "Performance evaluation of velocity observer for accurate estimation of servo motor drives," IEEE Trans. Ind. Appl., vol. 36, no. 1, pp. 98-104, Jan./Feb. 2000.

[16] A. Baehr and P. Mutschler, "Comparison of speed acquisition methods based on sinusoidal encoder signals," J. Electr. Eng., vol. 2, no. 1, Jan.-Jun. 2002, CD-ROM.

[17] A. Lonsdale, "Dynamic rotary torque measurement using surface acoustic waves," Sensors, vol. 18, no. 10, pp. 51-56, 2001

[18] G. Zhang and J. Furusho, "Speed control of a two-inertia system by PI/PID control," IEEE Trans. Ind. Electron., vol. 47, no. 3, pp. 603-609, Jun. 2000.

[19] Y. Hori, H. Sawada, and Y. Chun, "Slow resonance ratio control for vibration suppression and disturbance rejection in torsional system," IEEE Trans. Ind. Electron., vol. 46, no. 1, pp. 162-168, Feb. 1999.

[20] B. Drury, "The control techniques drives and controls handbook," in IEE Power and Energy Series 35. Stevenage, U.K.: Inst. Electr. Eng., 2001.

[21] G. Franklin, J. D. Powell, and A. Emami-Naeini, Feedback Control of Dynamic Systems. Englewood Cliffs, NJ: Prentice-Hall, 2002.

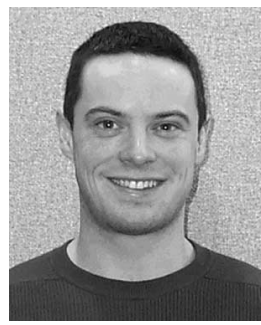

Timothy M. O'Sullivan received the M.Eng. degree in 2000 from the Department of Electronic and Electrical Engineering, University of Sheffield, Sheffield, U.K., where he is currently working toward the Ph.D. degree. His Ph.D. thesis is on the use of surface acoustic wave (SAW) torque transducers for improving the dynamic response of industrial servo-drive systems. 


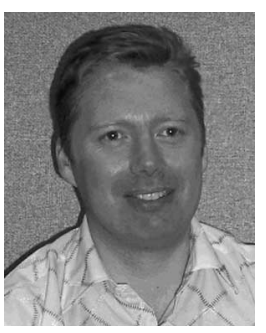

Christopher M. Bingham (M'00) received the B.Eng. degree in electronic systems and control engineering from Sheffield City Polytechnic, Sheffield, U.K., in 1989, the M.Sc. (Eng.) degree in control systems engineering from the University of Sheffield, Sheffield, in 1990, and the Ph.D. degree from Cranfield University, Bedfordshire, U.K., in 1994, for research on control systems to accommodate nonlinear dynamic effects in aerospace flight-surface actuators.

He was a Post-Doctoral Researcher at Cranfield University until subsequently taking up a research position at the University of Sheffield. Since 1998, he has been a Lecturer in the Department of Electronic and Electrical Engineering, University of Sheffield. His current research interests include traction control/ antilock braking systems for electric vehicles, electromechanical actuation of flight control surfaces, control of active magnetic bearings for high-speed machines, sensorless control of brushless machines, and analysis and design of resonant converter systems.

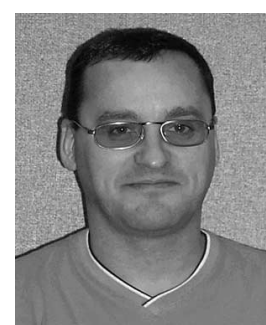

Nigel Schofield received the B.Eng. degree in electrical power engineering and the Ph.D. degree on the field weakening of brushless permanent-magnet traction machines from the University of Sheffield, Sheffield, U.K., in 1990 and 1997, respectively.

From 1993 to 1995, he was a Senior Experimental Officer in the Department of Electronic and Electrical Engineering (EEE) before taking up the post of Design Engineer in industry. From 1997 to 2000, he was a Post-Doctoral Researcher in the Electrical Machines and Drives Research Group, Department of EEE, University of Sheffield, and from 2000 to 2004, a Lecturer in the same department. On July 1, 2004, he was appointed to a Mechatronics Lectureship at the School of Electrical and Electronic Engineering, University of Manchester, Manchester, U.K. His research interests include electromagnetic power trains for all- and hybrid-electric vehicles, the vehicular application of hydrogen fuel cell systems, aerospace machines and actuators, and industrial applications of electromagnetic devices. 